\title{
Veracidade e narrativa: os critérios de verdade na entrevista de Bolsonaro ao Jornal Nacional
}

Veracity and narrative: the criteria of truth in Bolsonaro's interview with Jornal Nacional

Veracidad y narrativa: los criterios de verdad en la entrevista de Bolsonaro a Jornal Nacional

DOI: https://doi.org/10.1590/1809-58442021210

Julia Lery
https://orcid.org/0000-0002-4872-3561

Paulo Basilio Santana ${ }^{2}$

https://orcid.org/0000-0003-3089-698X

${ }_{1}^{1}$ (Pontifícia Universidade Católica do Rio de Janeiro, Departamento de Comunicação, Programa de PósGraduação em Comunicação. Rio de Janeiro - RJ, Brasil).

2(Pontifícia Universidade Católica de Minas Gerais, Faculdade de Comunicação e Artes, Programa de PósGraduação em Comunicação Social. Belo Horizonte - MG, Brasil).

\section{Resumo}

O trabalho propõe uma investigação acerca dos critérios de verdade que sustentam a entrevista que Bolsonaro, quando candidato, deu ao Jornal Nacional no dia 28 de agosto de 2018, bem como da checagem simultânea feita pela Agência Lupa. A busca é por compreender quais os mecanismos que dão veracidade à fala do candidato e quais são reivindicados pela checagem. Para isso, trabalhamos com os conceitos de verdade (ARENDT, 1972), mentira (DERRIDA, 1996) e narrativa (FIGUEIREDO, 2016, PIGLIA, 2001).

Palavras-chave: Fake news. Verdade. Checagem.

\begin{abstract}
The work proposes an investigation into the truth criteria that underpin the interview that Bolsonaro, as a candidate, gave to Jornal Nacional on August 28, 2018, as well as the simultaneous check done by Agência Lupa. The search is to understand which mechanisms give veracity to the candidate's speech and which are claimed by the check. For this, we work with the concepts of truth (ARENDT, 1972), lie (DERRIDA, 1996) and narrative (FIGUEIREDO, 2016, PIGLIA, 2001).
\end{abstract}

Keywords: Fake news. Truth. Check. 


\section{Resumén}

El trabajo propone una investigación sobre los criterios de verdad que sustentan la entrevista que Bolsonaro, como candidato, concedió a Jornal Nacional el 28 de agosto de 2018, así como la verificación simultánea realizada por Agência Lupa. La búsqueda consiste en comprender qué mecanismos dan veracidad al discurso del candidato y cuáles son los reclamados por el cheque. Para ello, trabajamos con los conceptos de verdad (ARENDT, 1972), mentira (DERRIDA, 1996) y narrativa (FIGUEIREDO, 2016, PIGLIA, 2001).

Palavras clabe: Fake News, verdad, cheque.

\section{Introdução}

Em entrevista ao Jornal Nacional (Rede Globo) no dia 28 de agosto de 2018 ${ }^{1}$, o então candidato à presidência pelo PSL-RJ, Jair Bolsonaro, levou um livro de capa roxa que afirmou ser parte de um "kit gay” distribuído nas escolas públicas do Brasil. A afirmativa veio como resposta a uma pergunta da âncora Renata Vasconcellos, que questionava o presidenciável sobre posicionamentos homofóbicos. De acordo com Bolsonaro, não era uma questão de homofobia, mas ele se opunha ao ensinamento de homossexualidade nas escolas, materializado naquele livro, que teria sido distribuído como parte do "kit gay" e ensinaria às crianças questões ligadas à homossexualidade. "Eu estava defendendo as crianças em sala de aula em todos os momentos”, afirmava o então candidato.

Começa, então, uma competição pelo uso das imagens como promessas de verdade na entrevista do telejornal. Os âncoras pedem que Bolsonaro guarde o livro, pois é vetado aos entrevistados mostrar documentos. $\mathrm{O}$ candidato pede aos espectadores que tirem as crianças da sala e promete uma live ${ }^{2}$ nas redes sociais mostrando o livro como prova do que dizia (e livre da mediação do Jornal Nacional). A câmera, antes fechada na imagem de Bolsonaro (Figura 1), muda para um plano aberto em que deixa de ser possível ver o livro com detalhes (Figura 2). E a notícia falsa de um suposto "kit gay", que posteriormente foi desmentida pelo $\mathrm{TSE}^{3}$, ganhou espaço no telejornal de maior audiência do país. Em vez de questionar a veracidade da fala, a disputa travada entre apresentadores e entrevistado foi acerca do monopólio do uso da imagem, tida como sinônimo de verdade. Não se questionou em nenhum momento a real distribuição do livro, apenas de Bolsonaro devia ou não mostrálo. Com a live de Bolsonaro nas redes sociais imediatamente após o fim do telejornal, essa disputa pela imagem se mostra ainda mais infértil do que já parece quando notamos a falta de questionamento: o livro já tinha sido mostrado na entrevista e foi exibido por mais tempo ainda nas redes, usando o dissenso da entrevista em rede nacional como divulgação.

1 Parte de uma série de entrevistas a todos os presidenciáveis de 2018.

2 Transmissão ao vivo pela internet

3 Disponível em: https://congressoemfoco.uol.com.br/amp/eleicoes/tse-diz-que-kit-gay-nao-existiu-e-proibe-bolsonaro-dedisseminar-noticia-falsa/. Acesso em: 21 out. 2019. 
Figura 1 - Bolsonaro mostrando o livro

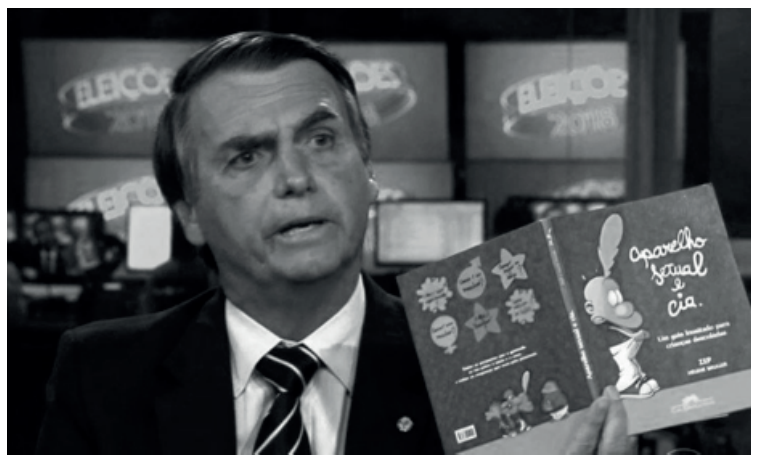

Fonte: Frame do Jornal Nacional.
Figura 2 - Plano aberto

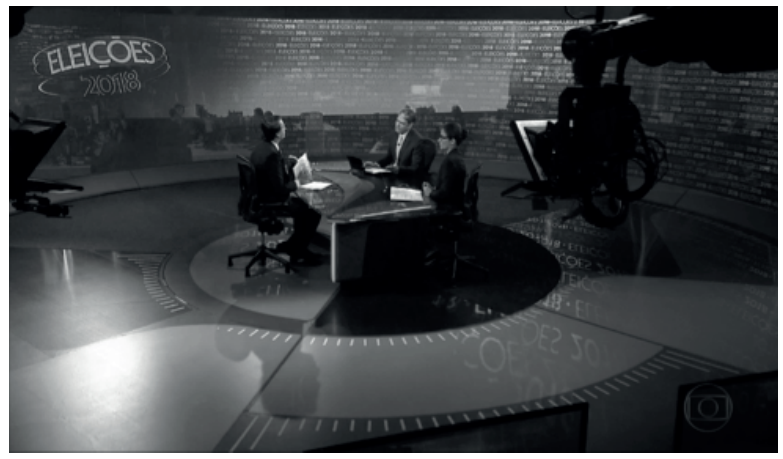

Fonte: Frame do Jornal Nacional.

A checagem que ocorreu paralelamente à entrevista, pela Agência Lupa, tampouco foi capaz de desmentir o que William Bonner e Renata Vasconcellos não questionaram. A editora, Cia das Letras, e o MEC, posteriormente, lançaram notas explicando que o livro nunca tinha sido distribuído em escolas públicas, que era um livro suíço e indicado para crianças de 11 a 15 anos, ao contrário do que o candidato dizia. Mas o alcance dessas notas é limitado se comparado à circulação de uma entrevista exibida no Jornal Nacional.

A partir desse caso, em que Jair Bolsonaro usa uma entrevista em um telejornal para a veiculação de uma notícia falsa, surge o questionamento acerca dos critérios de verdade reivindicados pelo então candidato na entrevista, bem como sobre qual é a verdade checada pela Agência Lupa. As perguntas que nos orientam são, assim, relacionadas à ideia de verdade que existe por trás dos discursos do candidato, dos apresentadores e da checagem.

\section{Percurso metodológico}

Partimos do seguinte problema: quais os critérios usados por Jair Bolsonaro, quando candidato, e pelos âncoras do Jornal Nacional para reivindicar verdade para suas falas durante a entrevista? Quais, ainda, os critérios usados pela agência de checagem para classificar as falas do entrevistado como verdades ou mentiras? Esses critérios são suficientes para questionar a fala do candidato?

A proposta, aqui, é empreender a análise de discurso audiovisual na entrevista televisiva a partir de referenciais teóricos que discutem os conceitos de verdade, mentira e narrativa. As categorias analíticas que nortearão o estudo e que serão teoricamente justificadas e apresentadas ao longo do texto são, aqui, apresentadas na ordem em que aparecem: o uso da imagem-prova (RANCIÈRE, 2014); a reivindicação da verdade a partir da experiência pessoal e fragmentada (FIGUEIREDO, 2016, 2017); o uso de metáforas (PIGLIA, 2001); as verdades do fato em conflito (ARENDT, 1972); a insuficiência do pensamento dicotômico entre verdade e mentira (DERRIDA, 1996). 
A partir dessas categorias, e apontando para a forma como elas são transversais e transdisciplinares, empreendemos a análise tanto da entrevista, quanto da checagem.

\section{Verdade e política}

Para Arendt (2016), a verdade é múltipla. Há a verdade da razão, aquela que não é vista de forma dada, tampouco revelada à humanidade, mas, sim, como um produto do tempo e de seus esforços. É uma verdade construída a partir de teorias e matemática, ciência e filosofia são alguns exemplos. Existe, por outro lado, a verdade do fato, que é composta de fatos e acontecimentos “incontestáveis”. Essa verdade é passada de pessoa para pessoa por meio do relato de quem viveu determinados acontecimentos. Ainda que esse relato esteja ligado a uma interpretação, a história não é livre para modificar uma verdade factual. Como exemplo dessa verdade do fato, Arendt (2016, p. 357) afirma sobre as interpretações possíveis da Primeira Guerra Mundial: “tenho certeza que não dirão que a Bélgica invadiu a Alemanha”.

Há, na leitura de Arendt (2016) sobre a verdade, uma ideia de que ela prevalece sobre a mentira, de que há algo de incontestável no fato que se sobrepõe a qualquer confabulação. A autora entende que a mentira é uma das ferramentas mais antigas da política, mas afirma que ela é relativamente bem vista por não ser um fim em si, mas um meio que por vezes pode evitar formas mais violentas de conflito. A mentira política, no entanto, costumava se validar em sua semelhança e aproximação com verdade. A mentira política moderna, por sua vez, se diferencia da anterior justamente por não buscar essa legitimação na verdade ou no acontecimento. Para Arendt (2016), que tem como referências os totalitarismos, a modernidade mente "em plena luz do dia", sobre fenômenos que a população viveu e não sobre segredos de Estado.

Derrida (1996), citando Arendt (2016), fala sobre a capacidade dos meios de comunicação de massas de falsearem verdades por meio de imagens. As mentiras políticas modernas, diferente das anteriores, tratam de coisas que não são segredos de forma alguma, de fatos conhecidos por todos, mas falseiam essas realidades, substituindo-as por imagens. Para Arendt (2016), portanto, ainda que exista uma verdade factual, a produção das narrativas que ganham o status de verdade se dá através de relatos. Ela destaca, ainda, o papel das imagens como responsáveis por carregar a verdade. As imagens podem endossar esses relatos mentirosos, trazendo veracidade.

Para Ranciére (2014), um problema na representação se dá quando passamos a entender as imagens como provas e não como um testemunho ou uma versão do acontecimento. O autor ressalta que "a imagem não é o duplo de uma coisa. É um jogo complexo de relações entre o visível e o invisível, o visível e a palavra, o dito e o não dito” (RANCIÈRE, 2014, p. 92). Ela é, porém, em muitos casos, lida como equivalente ao objeto representado.

Essa ideia de imagem-prova é forte em nossa sociedade e fica bem demarcada quando pensamos na profusão de vídeos de câmeras de segurança, transmissões televisivas ao 
vivo e até mesmo na arbitragem de vídeo, recentemente adotada pelo futebol. No discurso de Bolsonaro, é possível notar não apenas a força da ideia de que a imagem é capaz de provar algo, mas também uma sugestão de que a imagem seria o único tipo de evidência aceitável de um acontecimento. Quando interrogado por Renata Vasconcellos sobre sua polêmica fala de que mulheres deveriam ter salários menores do que homens, já que podem engravidar, o candidato reagiu: “Renata, você leu isso, ouviu ou viu?”. Quando a apresentadora responde que leu e ouviu, o candidato disse que ela não viu porque não tinha vídeo e que ele nunca falou essa frase. Assim, ele reivindica uma evidência audiovisual não só como prova, mas como a única prova possível. A verdade, no discurso de Bolsonaro estaria contida na imagem.

A partir dessa discussão é possível pensar na condição de imagem-prova que ganha o livro mostrado por Jair Bolsonaro como parte do "kit gay". Ainda que a verdade dos fatos (ARENDT, 2016) esteja amplamente disponível, ou seja, ainda que qualquer cidadão com filhos matriculados em escolas públicas tenha acesso ao material didático, o poder de persuasão da imagem se sobrepõe a essa verdade factual e de fácil acesso. Mente-se "em plena luz do dia”. Cria-se, com essas imagens, uma narrativa, um relato organizador interessado.

\section{Verdade e narrativa}

Usamos o conceito de narrativa para analisar o caso escolhido pensando em sua aproximação com os conceitos de confabulação, intriga, mentira ou relato interessado, e pensamos e sua oposição à verdade, a partir de discussão proposta por Figueiredo (2017) com base em Arendt (2016) e Derrida (2006). Não fazemos, portanto, uma referência à narrativa em seu sentido estrutural, que envolve enredo e narrador, mas, sim, falas que constroem o panorama de um projeto político ou do repertório comum. Nosso entendimento do conceito de narrativa é, assim, como uma forma de organização do mundo, um fio condutor sem o qual os fatos não se transformam em acontecimentos e a apreensão não se transforma em compreensão. Narrar é dar sentido, organizar.

A narrativa no sentido de relato organizador interessado não é, por si só, boa ou ruim, progressista ou reacionária. Para que possamos entrar nesse tipo de classificação, a questão que se coloca é quem detém esse poder de organizar acontecimentos em explicações, visões de mundo, encadeamentos de causas e consequências, e que uso se faz desse poder.

Mesmo o conceito de mentira não parece absoluto. Derrida (1996) aponta para o fato de que acusar alguém de mentir pressupõe ciência de uma intencionalidade insondável. Além de não acreditar, como Arendt (2016), que a verdade se sobrepõe à mentira, o filósofo afirma que as fronteiras são tênues. Ele propõe, portanto, que, para além do juízo insuficiente entre verdade e mentira, é necessária uma outra maneira de valoração dos enunciados.

o valor de um enunciado a respeito de fatos reais (pois a verdade não é a realidade, mas antes de tudo um enunciado em conformidade com aquilo 
que pensamos) poderia depender de uma interpretação política no tocante a valores, heterogêneos, aliás (possibilidade, oportunidade, necessidade, justeza ou justiça) (DERRIDA, 1996, p. 18).

Piglia (2001), buscando essa valoração dos enunciados, acredita que o problema do exercício de poder relativo às narrativas é que o Estado detém o poder de narrar e que o faz tanto criando histórias de violência quanto histórias que servem para ocultá-la. Para ele, as narrativas do poder são narrativas didáticas, histórias com moral e também histórias de terror. A busca do autor é por uma voz popular, por relatos dispersos, fragmentados, parciais, que podem, somados, dar conta de enfrentar essas ficções oficiais. Piglia (2001) equipara, de certa forma, narrativa, ficção e mentira ao falar sobre as narrativas do Estado. A ideia de narrativa para o autor se aproxima de um discurso oficial. O contra-discurso popular, para o autor, aparece de maneira mais fragmentada. Ambos os discursos, tanto a narrativa oficial quanto os relatos populares, são pensados para além do texto, como algo vivo que circula na cultura.

Em uma reflexão sobre os critérios de verdade dos enunciados, Figueiredo (2016) afirma que a autorreferencialidade se torna central na contemporaneidade, marcada pela crescente desconfiança em torno do ato de narrar. Para a autora, a descrença na possibilidade de se atingir uma verdade última, somada ao medo de uma narrativização do mundo pela mídia e uma angústia decorrente de uma percepção fragmentada da realidade faz com que os sujeitos contemporâneos se voltem cada vez mais para as narrativas pessoais, testemunhais e memorialísticas. Essa virada dos relatos, que já não buscam dar conta de uma universalidade, pode ser verificada na literatura, no cinema, na mídia.

A argumentação da autora passa pela ideia de que o ideal moderno de verdade fica desacreditado a partir dos totalitarismos do século XX e a percepção da história como uma construção narrativa pode, em seu extremo, equiparar história e ficção. A autora parece, assim, reivindicar o espaço de resistência que a ficção e as narrativas podem ocupar e criticar a perspectiva que equivale narrativas e totalizações, compreendendo que isso é mais relativo ao lugar de poder do que ao ato, em si, de criar um relato organizador.

Neste processo, fica evidente que os critérios de verdade das narrativas se alteram com o tempo, passando da busca por uma verdade universal para a busca por verdades menores, testemunhais, ligadas à experiência. A questão colocada por Figueiredo (2016, 2017), porém, é que essa fragmentação do narrar também pode servir ao poder e aos discursos excludentes, tanto quanto as narrativas que buscavam dar conta de verdades maiores.

Como exemplo de um momento em que a reivindicação da verdade se dá, na fala de Bolsonaro, a partir dessa ideia de verdades menores, ligadas à experiência, observamos a metáfora que o candidato usa para justificar a escolha antecipada do nome que ocuparia o Ministério da Fazenda. Quando questionado por William Bonner se não ficaria refém de Paulo Guedes, uma vez que assume que não entende nada de economia e lançou o nome do indicado a ministro ainda durante a candidatura, prometendo não romper com ele, Bolsonaro afirma que sua ligação com Guedes é de confiança, como em um casamento. Diz para o 
entrevistador que ambos são homens divorciados e que, por isso, sabem que não se casa pensando em terminar. Ao comparar as duas situações, o candidato enfatiza a dimensão de experiência pessoal que serve para legitimar sua fala pouco embasada sobre os rumos econômicos, relacionando essa questão, que tradicionalmente parece distante e de difícil compreensão, à vivência cotidiana de parte do eleitorado, conquistando assim um efeito de verdade. A metáfora desconsidera o caráter de interesse público da relação entre candidato e possível ministro e ainda traz à tona a vida pessoal do apresentador, trabalhando com as fronteiras tênues entre o público e o privado e enfatizando a experiência cotidiana, a verdade menor, o vivido. Ela não cria uma narrativa, no sentido de um relato organizador maior, mas nem por isso é mais verdadeira.

Piglia (2001) fala das metáforas usadas pelo poder como ficções do Estado. Ele afirma que a metáfora médica que a Ditadura Militar Argentina usava para se referir à repressão exemplifica perfeitamente como essas ficções são criadas. Segundo o autor, os militares falavam da Argentina como um corpo enfermo, com tumores, e que era necessário mutilar para salvar. Criava-se, assim, uma narrativa, um relato asséptico sobre a repressão, falando sobre cirurgias sem anestesia. E esse discurso era como uma versão ficcional por meio da qual o Estado enunciava a repressão, os assassinatos e as torturas, mas de um modo encoberto e alegórico.

Quando algo é enunciado por meio de metáfora, não se aplica um questionamento acerca da verdade ou da mentira da situação. Por isso, essa fala de Bolsonaro sequer é checada pela Agência Lupa. As agências de checagem lidam com verdades tidas por Derrida (1996) como naturais, em oposição aos que o autor chama de verdades performáticas. As verdades naturais são mais factuais e menos relativizáveis. As performáticas não são, exatamente, o oposto da mentira, mas verdades que se encontram para além dessa dicotomia, como a metáfora do candidato.

Ainda que a Agência Lupa crie as categorias denominadas "verdadeiro, mas", “exagerado” e “contraditório” para apresentar ressalvas à oposição estrita entre verdade e mentira, não há critérios que permitem avaliar a consistência de uma metáfora. Entre as dez afirmações de Bolsonaro apuradas pela Lupa, não consta, portanto, a relação entre plano econômico e casamento. Ainda assim, essa fala cria um critério de verdade baseado na performance, que esconde a inconsistência do discurso.

\section{Verdade e conflito}

O candidato não é, contudo, o único a reivindicar determinados critérios de verdade na busca de legitimação de suas falas. Os âncoras do telejornal estabelecem um estilo de entrevista combativo, que é adotado ao menos desde as eleições de 2014, no qual prevalece a ideia da verdade da denúncia. A entrevista seria mais verdadeira na medida em que é mais combativa. Há, assim, muitas interrupções por parte dos âncoras, a tentativa de "resumir" a fala do candidato, um reforço da hierarquia entre entrevistador e entrevistado com o controle 
rígido do tempo e exigência de monopólio de documentos e imagem. O que se dá, assim, é uma disputa discursiva com reivindicação de verdades por dois lados. Os entrevistadores também buscam declarar como verdadeiras as próprias versões dos acontecimentos.

O conflito mais evidente nesse sentido se dá no momento em que Jair Bolsonaro, respondendo a uma pergunta sobre a defesa de seu vice, General Mourão, à Ditadura Militar, cita palavras de Roberto Marinho, fundador da Rede Globo, para defender que o que aconteceu em 1964 teria sido uma revolução democrática. Sob protestos de William Bonner, Bolsonaro reivindica uma verdade histórica, factual, ao citar: "Participamos da revolução democrática de 1964 identificados com os anseios nacionais de preservação das instituições democráticas ameaçadas pela radicalização ideológica, distúrbios sociais, greves e corrupção generalizada”, atribuindo, com precisão, as palavras a Roberto Marinho. Ele pergunta, ainda, em tom de provocação: "Roberto Marinho foi um ditador ou um democrata?”.

Essa verdade (a afirmação de Roberto Marinho) factual e histórica, contudo, recorre à legitimação da fala por meio da credibilidade que uma figura que, naquele contexto, não podia ser questionada. Roberto Marinho, já falecido, era dono e fundador da Rede Globo, a emissora do jornal, e, de fato, apoiou o golpe militar de 1964 no Brasil, orientando a emissora, em um primeiro momento, a fazer o mesmo. Neste episódio, a verdade dos fatos de Arendt (2016) embasa tanto a fala de Bolsonaro sobre o apoio de Roberto Marinho à Ditadura Militar quanto a fala oposta que a confronta, de Bonner, que afirma que os historiadores reconhecem o ocorrido de 1964 como um golpe. Bolsonaro, se engajando nessa disputa de narrativas embasadas em verdades factuais, afirma: “deixa os historiadores para lá. Eu fico com Roberto Marinho”. Não há, neste caso, mentira ou erro. A legitimação da fala vem pela credibilidade que o espectador pode atribuir à figura de Roberto Marinho. Novamente, a checagem tem sua atuação limitada, uma vez que a afirmativa de Bolsonaro é factualmente correta. A citação de Roberto Marinho, assim como a metáfora do casamento, funciona como uma blindagem do discurso.

Tiburi (2017) afirma que o que é conhecido contemporaneamente como pós-verdade está relacionado exatamente à credibilidade de quem diz. Isso nos ajuda a compreender a efetividade da citação de Roberto Marinho por Bolsonaro (além, é claro, da evidente provocação). Para a autora, essa expressão pós-verdade surge de uma necessidade de compreender, a partir de uma ótica contemporânea, a relação de proximidade entre verdade e mentira já postulada por Arendt (2016) e Derrida (2006). Tiburi (2017) afirma, assim, que a pós-verdade é uma mentira bem aceita, que não cobra verdade argumentativa ou lógica e que, por isso, em última instância, é de responsabilidade do público, pois é ele quem escolhe como verdade o que lhe soar melhor ou mais conveniente. "A verdade é o palatável. E o palatável é suportável. A verdade depende, de algum modo, de nosso gosto” (TIBURI, 2017, p. 100). Vivemos, segundo Tiburi (2017), em um mercado de verdades, em que elas nos são oferecidas para consumo, como marcas, e escolhemos a que queremos. 
Nota-se, portanto, que a dicotomia entre verdade e mentira, embora seja muito potente na manutenção de arestas que orientam uma análise ética do discurso, parece insuficiente para dar conta de todas as nuances que funcionam como blindagens e como critérios de verdade. Recorremos, assim, a Derrida (1996), que propõe que não se tome os conceitos de verdade e mentira como dados. O autor pensa a mentira diferindo-a do erro, da inverdade, da fabulação, da ignorância. A mentira pressupõe uma intencionalidade que, em última instância, é inapreensível. Aponta para a impossibilidade de acusar alguém de mentir, pois exigiria um juízo de intenção. Derrida denomina contra-verité, ou contraverdade, um enunciado falso que ganha efeito de verdade. Para ele, o poder capitalísticotecnológico da mídia faz com que ela seja capaz de criar esses efeitos. Contemporaneamente, chamamos esses enunciados de fake news e tendemos a atribuir sua circulação à internet, nos esquecendo de que também podem estar (e estão, conforme demonstrado) presentes nos telejornais.

Pontuamos aqui que existe uma relação de continuidade planejada entre as falas de Jair Bolsonaro no maior telejornal do país e as fake news que sua equipe postava nas redes sociais. A entrevista na televisão funcionou, neste caso, para dar visibilidade e veracidade à mentira que, depois, o candidato contou mais livremente em sua live nas redes, sem a intervenção dos âncoras, como ficou claro no caso do livro.

É interessante notar ainda que, na lógica da força, mas ao mesmo tempo da insuficiência da dicotomia entre verdade e mentira, o próprio título da checagem da Agência Lupa evita a aberta acusação de mentira. Embora o corpo da matéria classifique as afirmações em “falso”, “verdadeiro”, “exagerado”, “verdadeiro, mas” e “contraditório”, o título fala em "erros e acertos” de Jair Bolsonaro, apagando a diferença epistemológica que Derrida aponta entre erro e mentira: não há mentira sem má fé. O que se nota, assim, quando a matéria da Agência Lupa equipara erro e falsidade, é que não há intenção de fazer um juízo de intencionalidade. Não há, da parte da agência de checagem, um juízo moral, como o que é reivindicado pelo candidato em suas falas. A ideia que parece prevalecer na checagem de fatos é a de verdade como um valor máximo, em que o erro, a falsidade e o exagero se equiparam. Há, ainda, uma ideia de verdade factual possível e, em alguma medida, verificável, que dialoga com a ideia de verdade do fato de Arendt (2016). Apesar do surgimento contemporâneo das agências de checagem (o site da Agência Lupa fala sobre as primeiras checagens que seguem este modelo terem acontecido nos Estados Unidos em 1991), o ideal de verdade factual que as embasa é moderno, como o defendido por Arendt (2016), e se afasta do relativismo proposto por Derrida (1996).

\section{Considerações finais}

Longe de propor uma conclusão, mas com o intuito de apresentar uma leitura e abrir uma discussão sobre a verdade, a mentira, a narrativa e os critérios de verdade 
reivindicados na entrevista e na checagem, partimos para a retomada e ênfase de alguns dos pontos abordados.

Notamos que os critérios de verdade das falas são os mais variados. Vão desde a reivindicação de verdades factuais, passando pelo uso da imagem-prova, por verdades fundamentadas em perspectivas políticas pré-determinadas e por verdades performáticas. Há fragmentação nos discursos, recorrendo a experiências pessoais, mas também a construção de uma narrativa, no sentido amplo e menos formalista da palavra. Uma narrativa como um relato parcial dos fatos. Podemos observar na entrevista, ainda, o processo descrito por Arendt (2016) de construção de uma mentira moderna, “em plena luz do dia”, ou seja, uma narrativa criada que se sobrepõe à experiência comum.

A agência de checagem, por sua vez, reivindica uma verdade jornalística cujo valor está estritamente relacionado à verdade factual e parte do pressuposto de Arendt (2016) de que há uma verdade dos fatos que persiste e resiste à ideia de mentira generalizada. Contudo, nem todas as afirmações podem ser checadas quando se adota essa perspectiva de verdade. As asserções que se legitimam por meio de metáforas, por exemplo, não podem ser julgadas pelo tradicional esquema que divide verdade e mentira, mesmo quando se cria outras categorias como "verdade, mas”, “contraditório” e “exagerado”. A dicotomia verdade e mentira é importante e potente, mas não dá conta da complexidade dos processos que dão valor de verdade à fala de Jair Bolsonaro na entrevista.

\section{Referências}

ARENDT, H. Entre o passado e o futuro. São Paulo: Perspectiva, 1972.

DERRIDA, J. História da mentira: prolegômenos. Estudos Avançados, v. 10, n. 27, 1996.

ESCÓSSIA, F. Ombudsman da Lupa: Lupa erra ao classificar como 'exagerada' afirmação 'falsa de Bolsonaro. São Paulo: Revista Piauí, Agência Lupa, 30 de agosto de 2018. Disponível em: https://piaui.folha. uol.com.br/lupa/2018/08/30/ombudsman-2-bolsonaro/. Acesso em: 25 set. 2018.

FIGUEIREDO, V. L. F. A narrativa sob suspeita: primeira pessoa e declínio da perspectiva utópica. In: DUARTE, M. R.; PALO, M. J. (Org.). Impasses do narrador e da narrativa. 1a. ed. São Paulo: EDUC, 2016, v. 1, p. 50-65.

FIGUEIREDO, V. L. F. Fiç̧ão e resistência na cultura de arquivo. In: XXVI ENCONTRO ANUAL DA COMPÓS, Faculdade Cásper Líbero, São Paulo - SP, 06 a 09 de junho de 2017. Anais....

JAIR BOLSONARO É ENTREVISTADO NO JORNAL NACIONAL. Jornal Nacional. Rio de Janeiro: Globo, 28 de agosto de 2018. Disponível em: https://globoplay.globo.com/v/6980200/. Acesso em: 25 set. 2018.

MARES, Chico et al. Erros e acertos de Jair Bolsonaro no Jornal Nacional e no Jornal das 10. São Paulo: Revista Piauí, Agência Lupa, 28 de agosto de 2018. Disponível em: https://piaui.folha.uol.com.br/ lupa/2018/08/28/jair-bolsonaro-tv-globo/. Acesso em: 25 set. 2018.

PIGLIA, R. Modos de narrar. In: PIGLIA, R. La forma inicial. Buenos Aires: Eterna cadencia editores, 2015. p. 43-53.

PIGLIA, R. Tres propuestas para el próximo milenio - y cinco dificultades. Buenos Aires: Fondo de Cultura Económica, 2001. 
RANCIERE, J. A imagem intolerável. In: RANCIERE, J. O espectador emancipado. São Paulo: Martins Fontes, 2014.

\section{Julia Lery}

Doutoranda em Comunicação Social pela Pontifícia Universidade Católica do Rio de Janeiro, linha de pesquisa Comunicação e Produção. Mestra em Comunicação Social pela Pontifícia Universidade Católica de Minas Gerais. E-mail: lery.julia@gmail.com.

\section{Paulo Basilio Santana}

Mestre em Comunicação Social pela Pontifícia Universidade Católica de Minas Gerais. E-mail: paulobasilio28@gmail.com.

Recebido em: 28.10.2019 Aprovado em: 16.09.2020 